Special issue in honor of Prof. George C. Papageorgiou

REVIEW

\title{
Photosystem II in bio-photovoltaic devices
}

\author{
R.A. VOLOSHIN*, S.M. SHUMILOVA*, E.V. ZADNEPROVSKAYA*, S.K. ZHARMUKHAMEDOV**, \\ S. ALWASEL ${ }^{* * *}$, H.J.M. HOU ${ }^{\#}$, and S.I. ALLAKHVERDIEV ${ }^{* * * * * * *,+}$
}

\author{
Controlled Photobiosynthesis Laboratory, K.A. Timiryazev Institute of Plant Physiology, Russian Academy \\ of Sciences, 127276 Moscow, Russia* \\ Institute of Basic Biological Problems, RAS, Pushchino, 142290 Moscow Region, Russia** \\ College of Science, King Saud University, Riyadh, Saudi Arabia*** \\ Laboratory of Forensic Analysis and Photosynthesis, Department of Physical/Forensic Sciences, Alabama \\ State University, Montgomery, 36104 Alabama, United States ${ }^{\#}$
}

\begin{abstract}
Hybrid photoelectrodes containing biological pigment-protein complexes can be used for environmentally friendly solar energy conversion, herbicide detection, and other applications. The total number of scientific publications on hybrid bio-based devices has grown rapidly over the past decades. Particular attention is paid to the integration of the complexes of PSII into photoelectrochemical devices. A notable feature of these complexes from a practical point of view is their ability to obtain electrons from abundant water. The utilization or imitation of the PSII functionality seems promising for all of the following: generating photoelectricity, photo-producing hydrogen, and detecting herbicides. This review summarizes recent advances in the development of hybrid devices based on PSII. In a brief historical review, we also highlighted the use of quinone-type bacterial reaction centers in hybrid devices. These proteins are the first from which the photoelectricity signal was detected. The photocurrent in these first systems, developed in the $70 \mathrm{~s}-80 \mathrm{~s}$, was about $1 \mathrm{nA} \mathrm{cm}^{-2}$. In the latest work, by Güzel et al. (2020), a stable current of about $888 \mu \mathrm{A} \mathrm{cm}^{-2}$ as achieved in a PSII-based solar cell. The present review is inspired by this impressive progress. The advantages, disadvantages, and future endeavors of PSII-inspired bio-photovoltaic devices are also presented.
\end{abstract}

Keywords: electron transfer; photoanode; photo-bioelectrochemical cell; photocurrent.

\section{Highlights}

- Reaction centers are promising for solar energy conversion

- Many types of photo-bioelectrochemical cells have been described in the literature

- The mesostructure of the electrode plays a key role in photocurrent generation
Received 30 May 2021

Accepted 18 February 2022

Published online 7 March 2022

Corresponding author

e-mail: suleyman.allakhverdiev@gmail.com

Abbreviations: ACVD - aerosol-controlled vapor deposition; bRC - bacterial reaction center; BSA - bovine serum albumin; DCBQ - 2,6-dichloro-1,4-benzoquinone; DET - direct electron transfer; EQE - external quantum efficiency; FF - fill factor; FTO - fluorine-doped tin oxide; Histag - six histidine residues motif; IO - inverse opal; IO-mesoITO - hierarchically structured inverse opal mesoporous indium tin oxide; IQE - internal quantum efficiency; $\mathrm{I}_{\mathrm{SC}}$ - short-circuit current; ITO - indium tin oxide; MET - mediated electron transfer; MF - Millipore membrane filter; Ni-NTA - Ni(II)-nitrilotriacetic acid; OEC - oxygen-evolving complex; $\mathrm{P}_{680}$ - PSII special pair; PBEC - photo-bioelectrochemical cell; PEM - proton exchange membrane; Pheo - pheophytin; $\mathrm{PVC}$ - polyvinyl chloride; $\mathrm{Q}_{\mathrm{B}} \mathrm{H}_{2}$ - plastoquinol $\mathrm{Q}_{\mathrm{B}} ; \mathrm{RC}$ - reaction center; $\mathrm{SAM}$ - self-assembling monolayer; $\mathrm{SSA}$ - specific surface area; $\mathrm{V}_{\mathrm{OC}}-$ open-circuit voltage.

Acknowledgments: We are grateful to Dr. Douglas Strout for his critical reading of the manuscript and for his constructive comments to improve the quality of the manuscript. SMS, RAV, SKZ, and SIA were supported by a grant from the Russian Science Foundation (No. 19-14-00118). Figs. 5 and 6 were supported by the grant of state assignment of Ministry of Science and Higher Education of the Russian Federation (No. 121033000136-4). SA would like to thank the Distinguished Scientists Fellowship Program, King Saud University, Saudi Arabia, for the support.

Conflict of interest: The authors declare that they have no conflict of interest. 


\section{Introduction}

The exponentially growing scientific interest in the practical application of primary photosynthetic processes is stimulated, on the one hand, by progress in understanding the mechanisms underlying photosynthesis, and on the other hand, by the problems faced by humanity. Let us briefly note the challenges for the meeting of which hybrid bio-based photovoltaic devices can be used.

Energy depletion and environmental degradation appear to be the most serious problems. The increase of the world's population leads to a rapid growth in energy demand, which is largely met by nonrenewable fossil fuels (Weijermars et al. 2012, IEA 2019). The problem of fossil fuel depletion and the deleterious effects of its use on the environment has long been discussed (Allen 1977, Kumar and Kuppam 2020). The consumption of such energy sources can be minimized by using alternative, environmentally friendly energy resources (Voloshin et al. 2015, Rodionova et al. 2017).

The Sun is the most promising energy source. It is providing more energy for the Earth in one hour than it is consumed by people in a year (Lewis and Nocera 2006). However, common semiconductor solar cells or solar cells based on artificial sensitizers have some disadvantages, including high production costs and associated environmental problems (Grätzel 2001, 2007; Chen et al. 2012, Musazade et al. 2018).

One of the alternative directions of solar energy harvesting is the utilization or imitation of native photosynthetic structures and mechanisms. Integration of the PSII pigment-protein complex of the oxygenic phototrophic organisms is of particular interest due to the possibility to generate photoelectrons from water (Pandey et al. 2016).

Another problem associated with human activity is the contamination of soil, water, and air by toxic chemicals. Among the multiple pollutants, some hamper both humans and inhibit the photosynthetic activity of plants. They include herbicides and heavy metals. These compounds originate from industrial waste effluents and agricultural run-off. Chemicals with a slow degradation rate can be accumulated in soil and surface water in high enough amounts undermining the health of the ecosystem. In developed countries, prohibitions are introduced on the use of certain herbicides and maximum permissible concentrations of these compounds in the soil are established (Touloupakis et al. 2005). The threshold level for herbicides is very low. For example, within the European Union, it is $0.5 \mu \mathrm{g} \mathrm{L}^{-1}$ for total pesticides (Merz et al. 1996). The herbicide control requires a convenient and sensitive system for the assessment of water and soil quality. The standard chromatographic method of herbicide detection is very sensitive and selective, however, at the same time, it is very complicated and cumbersome (Koblížek et al. 2002). Standard algal growth test, also used for herbicide detection, is less sensitive and needs more time (Masojídek et al. 2011). When we have to deal with herbicide inhibiting the photosynthetic activity, it seems quite logical to use photosynthetic pigment-protein complexes as sensory elements.
The bio-based hybrid electrode is the basis for all of the aforementioned PSII applications. The transfer of electrons from a natural pigment-protein complex to an inorganic component of the electrical circuit is a mandatory step in the energy conversion and detection of herbicides. The high performance of the photoinduced electron transfer reaction in the hybrid electrodes is important for all PSII photo-bioelectrochemical applications.

Another application of bio-based photoelectrodes is the investigation of the fundamental photosynthetic processes. Although common principles of photosynthesis are well known, there are many unknowns about particular features of electron and energy transfer and photosynthetic regulation and acclimation. There are several commonly used techniques for measuring the activity of the primary photosynthetic processes. They include chlorophyll fluorimetry, polarography, and flash spectroscopy (Walker et al. 1983, Walker 1993, Wiederrecht et al. 1994, Kalaji et al. 2014). Analysis of photoelectrochemical processes in the PSII-based hybrid electrodes offers another tool for photosynthesis monitoring (Seibert et al. 1982, Kato et al. 2014).

Notwithstanding the many years of persistent efforts, the main disadvantage of bio-based hybrid devices has not been overcome. It is the low stability of the biomolecules (Allakhverdiev et al. 2010a,b). One solution to this obstacle is to develop a completely artificial system that has the advantages of natural systems and, at the same time, is devoid of their disadvantages.

In this paper, we review the current literature on photo-bioelectrochemical devices based on PSII. We will describe only two areas of the pigment-protein complexes application: solar energy conversion and herbicide detection. In addition, one can find other photosystembased electrode applications in scientific literature, e.g., memory devices and light sensors (Nishiori et al. 2019, Güzel et al. 2020). The first section is a brief description of the PSII structure and its utility for electrochemical applications. The second section describes the materials most often used in PSII-based hybrid electrodes and the features of attaching photosystems to conductive substrates. The third section presents the analysis of different types of solar cells based on PSII. In the fourth section, the features of hydrogen production due to the PSII-based half cell of water splitting are briefly outlined. The fifth section focuses on PSII-based herbicide detection systems. The sixth section is devoted to artificial systems that mimic the native PSII.

\section{Photosystem II}

The first photoelectrochemistry measurements of photosynthetic components have been done with reaction centers (RC) of the purple bacteria (bRC) (Drachev et al. 1975, Packham et al. 1980). The promise of RC is because the quantum yield of charge separation in the photosynthetic RC is close to $100 \%$ (Emerson et al. 1957). RC of PSII is similar to bRC (Michel and Deisenhofer 1988). However, they show few differences (Müh et al. 2012). The higher stability of bRC favored the work on the bRC-based biohybrid photoelectrochemical cells (Maksimov et al. 
2013). Evolutionarily younger oxygenic photosynthesis was made possible by the combination of RC and oxygenevolving complex (OEC) into a PSII (Nisbet et al. 2007, Shevela et al. 2013). OEC is evolutionary innovation that allows splitting water photosynthetically (Nelson and Yocum 2006). When the energy of four light quanta is absorbed, the splitting of two water molecules produces four electrons, four protons, and one oxygen molecule (Cox and Messinger 2013). The energy of low-potential electrons from water is insufficient for the satisfaction of plant cell needs. Due to this, PSII in living cells works in tandem with PSI (Tikhonov 2013).

PSII-comprising RC, OEC, light-harvesting complexes, and several accessory and support protein subunits, is a finely tuned molecular machine. The sophisticated RC design allows it to convert light energy with a fairly high quantum yield (Wiederrecht et al. 1994). At the same time, PSII is very susceptible to damage by light and heat (Wang et al. 1992, Hakala et al. 2006, Dankov et al. 2015). This vulnerability is related to the water-splitting ability (Wang et al. 1992). Nevertheless, PSII is considered a promising agent for some different applications such as PSII-based biomimetic systems (Zhang and Reisner 2020, Xuan and Li 2021). Other photosynthetic pigment-protein complexes are also of very interest in the biohybrid devices area (Nguyen and Bruce 2014, Voloshin et al. 2015, Plumeré and Nowaczyk 2016, Friebe and Frese 2017). There are many developments of photo-bioelectrochemical cells based on components of the photosynthetic apparatus (PA), for example, based on thylakoids, PSI complexes, bacterial RCs (Kiley et al. 2005, Terasaki et al. 2006, 2009; Faulkner et al. 2008, Yehezkeli et al. 2014, Ridge Carter et al. 2016, Friebe and Frese 2017, Zhang and Reisner 2020). PSI and bacterial $\mathrm{RC}$ has more stability in comparison to PSII (Gall et al. 1998, Mershin et al. 2012, Yehezkeli et al. 2013, Nguyen and Bruce 2014). However, cells based on PSII are of special interest because unlike the other components of the photosynthetic apparatus, they do not need external electron donors other than water for photoinduced redox reactions to occur (Vogt et al. 2015). The fact that PSII generates protons from water under visible light is of particular interest from the point of view of designing systems for the production of molecular hydrogen.

A schematic of PSII of higher plants and its cofactors is depicted in Fig. 1. PsbQ, PsbP, and PsbO subunits stabilize and optimize the water-splitting complex and its reactivity. D1 and D2 subunits bind the cofactors of $\mathrm{RC}$ including special chlorophyll dimer (special pair, $\mathrm{P}_{680}$ ), pheophytin, quinone $\mathrm{A}$, and quinone $\mathrm{B}$. Antenna or light-harvesting complexes LHC 2 are responsible for the collection of light quanta and the transfer of quantum energy to the reaction center (Govindjee et al. 2010).

\section{PSII-based hybrid electrode}

\section{Substrate material for PSII immobilization}

In the literature, we find reports on bio-based hybrid electrodes of different designs. Gold, silver, indium tin

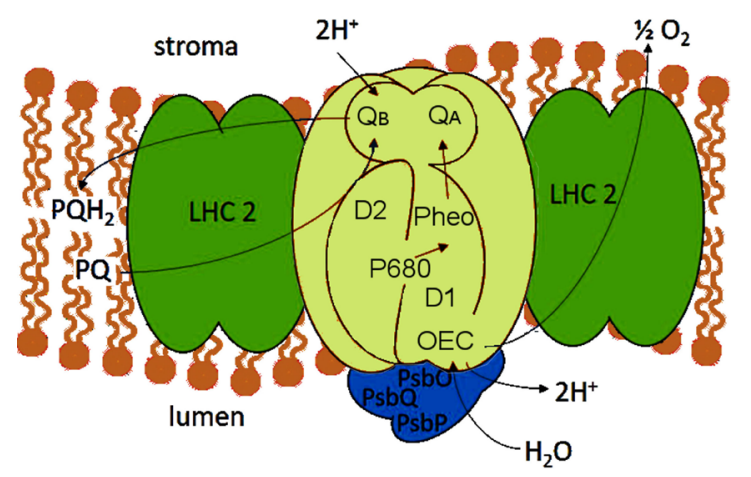

Fig. 1. The structure of the PSII. D1 and D2 are the reaction center proteins; LHC 2 - antenna light-harvesting complexes; OEC - oxygen-evolving complex; Pheo - pheophytin; PsbQ, PsbP, and PsbO - subunits of the OEC; $\mathrm{P}_{680}$ - PSII special pair; $\mathrm{PQ}$ and $\mathrm{PQH}_{2}$ - oxidized and reduced form of the mobile plastoquinone molecules; $\mathrm{Q}_{\mathrm{A}}$ - the first bound quinone acceptor of PSII; $\mathrm{Q}_{\mathrm{B}}$ - the second quinone acceptor. Adapted from Govindjee et al. (2010).

oxide, fluorine-doped tin oxide, and various forms of carbon are used as the conductive material of the electrodes (Malý et al. 2005b, Trammell et al. 2006, Kato et al. 2013, Friebe et al. 2017, Szewczyk et al. 2020). Let us consider in more detail the features of these materials.

Biological components should function stably after immobilization onto the electrode, and inorganic components should be resistant to corrosion processes. Therefore, an important property of the used conductive electrode materials is their chemical inertness and biological compatibility. It is known that noble metals are inert. In addition, some allotropic carbon modifications (glassy carbon, carbon fiber, graphene) and wide-gap semiconductors such as titanium dioxide have similar properties (Grätzel 1999, Walsh et al. 2016).

Electrode materials must meet the requirement of high electrical conductivity. Silver, gold, and other noble metals have high electrical conductivity. However, since hybrid devices need to contain no expensive components to compete with traditional energy sources, researchers are looking for more affordable materials. Semiconductor materials allow more effective electron acceptance from the reaction center in comparison to metal. It can be associated with the prohibited reverse electron transfer in the semiconductor/RC interface that is not observed in the metal/RC interface. There is no significant photoelectron transfer between metal electrode and reaction center immobilized on it due to physical adsorption (Seibert et al. 1982). To obtain photocurrent in metal/RC electrodes, it is necessary to connect it chemically by a special linker (Terasaki et al. 2006, Trammell et al. 2006).

Wide-gap semiconductors, such as ITO and FTO, $\mathrm{TiO}_{2}$, are corrosion-resistant. They are often used as substrate material for electrodes (Nikandrov et al. 2012, Sokol et al. 2016, Szewczyk et al. 2020). The nanostructured $\mathrm{TiO}_{2}$ layer is commonly coated onto FTO- or ITO- 
glasses and such sandwich structure, in turn, adsorbs the photosynthetic material (Gizzie et al. 2015, Shah et al. 2015). ITO and FTO are applied to glass using various methods allowing the resulting conductive glass to remain transparent. Transparency is important for any photonic device. It should be noted that glasses with fluorine-doped tin oxide have an advantage over ITO glasses, since indium is not widely distributed in the Earth's crust, and this affects its cost (Frenzel et al. 2016).

Another important characteristic of the photoanode substrates is their specific or effective surface area (SSA) (Faure et al. 2013, Maksimov et al. 2013, Fu et al. 2017, Oshima et al. 2020). SSA is the real area of the surface that is intricately micro- and nanostructured in threedimensional space. This term is opposed to a geometrical surface area that is a macroscopically determined area of the 2D surface (Kato et al. 2014). The larger SSA, the more pigment-protein complexes can be immobilized onto the surface with the same geometrical surface area. Higher loading of the substrate by RC-contained complexes leads to the increasing absorption crosssection of the photoelectrode and, as a consequence, to a higher photocurrent signal. On the one hand, high porosity substrate has a higher SSA. On the other hand, pigment-protein complexes cannot be entrapped in very small pores (Zhang and Reisner 2020). Building the electrode with appropriate SSA for the specific pigmentprotein complexes loading is an important challenge for bio-based hybrid electrode design. There are many different methods to obtained nanostructured mesoporous materials with high SSA. They include salting out of the gold nanoparticles onto flat gold electrode (Terasaki et al. 2008, 2009), calcination of the layer of the $\mathrm{TiO}_{2}$ paste mixed with an organic template ( $\mathrm{Lu}$ et al. 2005a), anodic oxidative hydrolysis of $\mathrm{TiCl}_{3}$ (Kavan et al. 1993, Lu et al. 2005b), aerosol-controlled vapor deposition (ACVD) process of titanium tetraisopropoxide with consequence sintering (Shah et al. 2015, Kavadiya et al. 2016), calcination of the mixing of the ITO particles with polystyrene beads to obtain electrode with inverse opal architecture (Mersch et al. 2015, Sokol et al. 2016), simple one-step pyrolysis of yeast extract and $\mathrm{NaHCO}_{3}$ to prepare the carbon with interconnected porous networks (Tian et al. 2021), and others techniques.

The thickness of the electrode also affects its functionality. The large thickness of the nanostructured electrodes allows loading a larger number of $\mathrm{RC}$ complexes. At the same time, it should be a thin layer to minimize the electron diffusion length. Many different coating techniques are used to create a layer of conductive or semiconducting material of the desired thickness on an insulating plate. These include spin-coating, doctorblading, screen-printing, ACVD, and others (Shah et al. 2012, Kato et al. 2014, Yu et al. 2015, Voloshin et al. 2017).

Thus, the effectiveness and feasibility of using various materials as conductive substrates for PSII complexes are determined by such properties as electrical conductivity, SSA, chemical and biological inertness, cost, and availability of the materials used.

\section{Techniques of pigment-protein complex immobilization}

The orientation of the immobilized protein complexes and the efficiency of electron transfer to the conducting surface depends on the electrode material and the method of immobilization. In some cases, to obtain a significant photocurrent, mediators are used that carry out charge transfer between RCs that do not have direct contact with the electrode and the electrode itself. The electron transfer that is realized only in the presence of a mediator is called mediated electron transfer (MET). The electron transfer directly from adsorbed pigment-protein complexes to the electrode is called direct electron transfer (DET). DET is preferable because it suggests lower resistance to electron transfer (Hasan et al. 2017).

The general methods of immobilization include chemical anchoring due to linker, physical adsorption, and redox-gel entrapment.

(1) Fixation of pigment-protein complexes due to special linkers: As we noted above, linker-fixation techniques are used to establish electrical contact between the pigment-protein complexes and the metal electrode. The most common RC fixation with linkers occurs on a gold electrode (Lebedev et al. 2006). The most commonly used linkers are the self-assembling monolayer (SAM) layer together with the $\mathrm{Ni}(\mathrm{II})$-nitrilotriacetic acid (Terasaki et al. 2008).

SAM is a spontaneously formed one-molecule-thick layer on the surface of a specific substrate when the latter is immersed in a surfactant solution in an organic solvent. Since SAM formations from thiols and disulfides are known on the surface of a gold substrate, the PSII complex can be attached by covalent bonds to the finished SAM (Frolov et al. 2005, Malý et al. 2005b).

It should be noted that the efficiency of electron transfer from $\mathrm{RC}$ to the conductive substrate is influenced by the orientation of the pigment-protein complexes on the electrode. It was shown that the interaction of SAM with PSII, due to electrostatic or covalent forces, affects the orientation of the protein relative to the substrate. Kato et al. (2013) studied the photocurrent in hybrid cells based on the cyanobacteria PSII complexes. These sensitizers were electrostatically and covalently immobilized on a SAM-modified mesostructured ITO electrode. The results of the work showed that the orientation of the PSII obtained during immobilization due to electrostatic interaction provides the most efficient electron transfer. In this case, the subsequent covalent binding of such a PSII already oriented in a certain way provides higher values of the registered photocurrent than due to solely electrostatic bonds (Kato et al. 2013).

The use of a SAM as a linker together with Ni(II)nitrilotriacetic acid (Ni-NTA) requires genetic modification of the protein. In the case of PSII, one should use complexes with modified CP47 or CP43 subunits (Terasaki et al. 2008, Noji et al. 2011). They must have six consecutive histidine residues (Histag) at the C-terminus. In this case, the conductive surface is covered with an organic layer, then Ni-NTA is applied. Ni-NTA has a high affinity for the 
polypeptide chain in modified photosystems. The histidinelabeled PSII protein complex was covalently bound to a conductive Ni-NTA-treated gold surface (Fig. 2). In such a solar cell, according to the calculations of Vittadello et al. (2010), the current density should reach $43 \mu \mathrm{A} \mathrm{cm}^{-2}$. The interest of PSII-decorated gold electrode has been offered by Miyachi et al. (2017). In this system, PSII complexes were reconstituted by changing native quinone on the quinone derivative that is fixed on the platinum nanoparticle. One nanoparticle can fix multiple quinone derivatives. Thus, after the reconstruction and cross-linking agent adding, the interconnected net of the PSII complexes and Pt nanoparticle was obtained. This net was fixed onto the $\mathrm{Au} / \mathrm{SAM}$ electrode. Such a system can generate $15 \mathrm{nA} \mathrm{cm}{ }^{-2}$ at $\mathrm{E}=+0.10 \mathrm{~V}$ (vs. $\mathrm{Ag} / \mathrm{AgCl}$ ) under $680-\mathrm{nm}$ irradiation (Miyachi et al. 2017). Despite the small current

$A$

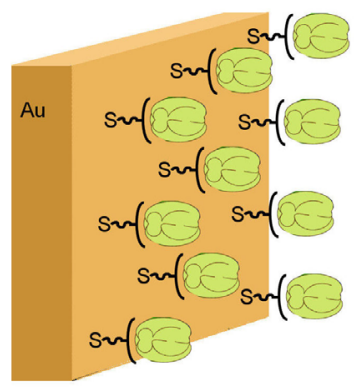

B

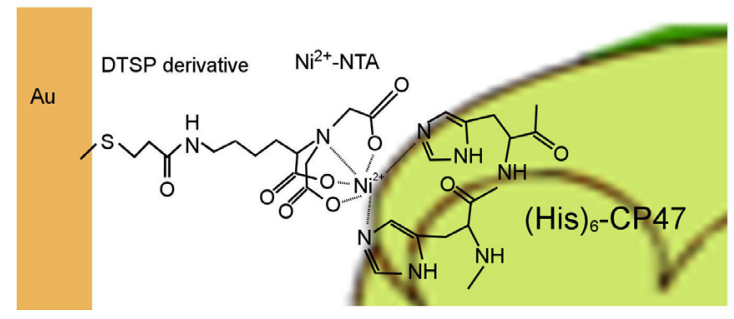

Fig. 2. Planar gold electrode with immobilized Histag-PSII through Ni-NTA SAM. General scheme $(A)$; scheme of Histag-PSII anchoring through 3,3'-dithiodipropionic acid di(N-hydroxysuccinimide ester) (DTSP) and $\mathrm{Ni}$ (II)-nitrilotriacetic (Ni-NTA) (B). Adopted from Terasaki et al. (2008) and Noji et al. (2011). value, this bio-based electrode is of interest because it used 'nanowire' between PSII complexes and the electrode. Wiring suggests the straight electron transfer: $\mathrm{P}_{680} \rightarrow \mathrm{Q}_{\mathrm{A}} \rightarrow \mathrm{Pt} \rightarrow$ gold electrode

It should be noted that the linker-based method of protein immobilization is expensive because it requires complex chemical and genetic modifications. However, further research in this area could lead to a reduction in the cost of this technique.

(2) Physical adsorption of pigment-protein complexes on a substrate: This method involves the use of semiconductor substrates based on nanostructured metal oxides (Fig. 3). A nanostructured layer differs from a flat one by the presence of cavities and pores several tens of nanometers in size. Nanoporous titanium dioxide $\left(\mathrm{TiO}_{2}\right)$ is most often used for solar cells because it is biocompatible and easily forms bonds with proteins through $\mathrm{COOH}$ groups, and the porous structure increases the strength of these bonds and increases the absorption cross-section (Yu et al. 2015).

Zaspa et al. (2020) measured photocurrent generated by PSII-based solar cell where the PSII core complexes were adsorbed onto a Millipore membrane filter (MF) on an ITO electrode. The stable and maximum photocurrent was recorded in the presence of trehalose and 2,6-dichloro1,4-benzoquinone (DCBQ). It was suggested that the long-term retention of photoactivity at room temperature in the structure ITO | PSII-MF | ITO may be associated with the retention of water molecules attached to the PSII surface in the presence of trehalose.

Brinkert et al. (2016) showed that in the system PSII $\left|\mathrm{TiO}_{2}\right|$ ITO, electron transfer occurs from the first quinone $\mathrm{Q}_{\mathrm{A}}$ directly to the ITO-conducting surface and the transfer of electrons through the nanostructured metal oxide is the rate-limiting stage. The authors considered the possibility of using oxides of other metals with a wider band gap, such as tin dioxide $\left(\mathrm{SnO}_{2}\right)$ or tungsten trioxide $\left(\mathrm{WO}_{3}\right)$ (Brinkert et al. 2016). The advantages of using this method include the convenience of obtaining a nanostructured surface, a lower cost, and a larger surface area compared to a gold electrode. However, the main disadvantage is the low efficiency of electron transfer to $\mathrm{TiO}_{2}$ and oxides of some other metals because electrons from PSII, entering the nanoporous metal oxide, have an

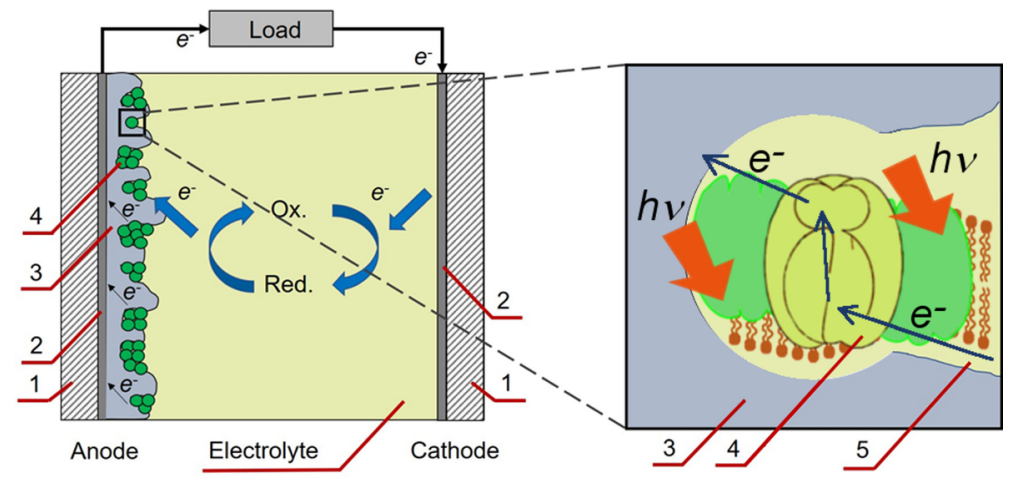

Fig. 3. An example of solar cell design based on PSII immobilized on a conductive substrate using the physical adsorption method. 1 - glass; 2 transparent conductive spraying; 3 - nanoporous $\mathrm{TiO}_{2} ; 4$ - photosynthetic RC; 5 - electrolyte; $\mathrm{RC}$ - reaction center; Ox. - the oxidized form of the electrolyte; Red. - the reduced form of the electrolyte. 
energy level below the conduction band of this material (Brinkert et al. 2016).

Güzel et al. (2020) suggest another interesting system of PSII complexes fixed onto the $\mathrm{TiO}_{2}$ electrode due to 'bio-nano-cocktail' production. They used the aminoacid (monomer) decorated and light underpinning conjugation approach for obtaining an array of the cross-linking PSII proteins with NADH linkage ruthenium-based amino acid monomer. This approach uses sensitizer properties of the chloro-bis(2-2'-bipyridyl) methacryloyl tyrosineruthenium(II) for the polymerization (Say et al. 2012). Resulted PSII-bio-nano-coctail was used as a sensitizer for BSSC. This BSSC generated an open circuit voltage of $0.50 \mathrm{~V}$, a short circuit current of $888 \mu \mathrm{A} \mathrm{cm}^{-2}$, and a fill factor of 0.50 (Güzel et al. 2020).

Another promising method of immobilization is the creation of a hierarchically structured reverse opal conducting surface based on mesostructured indium tin oxide (IO-mesoITO). The advantage of IO-mesoITO is that it has metal-like conductivity and biocompatibility, a large surface area due to the formation of channels (Brinkert et al. 2016, Sokol et al. 2016, Tian et al. 2021). IO-meso electrodes are considered the last most perspective generation for biohybrid devices. IO-meso electrodes are currently the most modern and promising technology in the field of biohybrid devices (Zhang and Reisner 2020).

(3) Fixation of pigment-protein complexes in redox hydrogels: The fixation of the PSII complexes in the polymer gel helps maintain stability while increasing the surface area of the coating with pigment-protein complexes. Immobilization of the photosystem complexes in a matrix of gelatin or bovine serum albumin and glyceraldehyde is a widely used method for assembling PSII-based biosensors (Giardi et al. 2001). Modification of such a gel with redox agents improves the transfer of electrons to the conductive substrate since redox agents act as electronic mediators. Osmium-containing redox polymer based on poly-1-vinylimidazole is widely used for fixing the photosystem (Badura et al. 2008, Kothe et al. 2013, Sokol et al. 2016). In these cells, the Osbased polymer acts as an electron mediator and as a matrix for fixing PSII complexes (Fig. 4).

One of the most effective PSII-based devices has been designed by Sokol et al. (2016). The authors combined the immobilization method in redox polymer with a mesostructured IO-mesoITO substrate, and obtained a photocurrent of up to $410 \mu \mathrm{A} \mathrm{cm} \mathrm{cm}^{-2}$ without mediators and up to $513 \mu \mathrm{A} \mathrm{cm}^{-2}$ in the presence of DCBQ.

Wang et al. (2020) observed an increase in the photocurrent density up to $70 \mu \mathrm{A} \mathrm{cm}^{-2}$ in the presence of dinoterb, a phenolic inhibitor of the $\mathrm{Q}_{\mathrm{B}}$-binding site in PSII. In this work, PSII complexes were immobilized through a redox polymer modified with osmium on a gold substrate. The authors assume that these results are associated with the effect of the used inhibitor on the polymer film and emphasize the importance of taking into account the possible effect of additional compounds on bioelectrodes modified by a redox polymer.

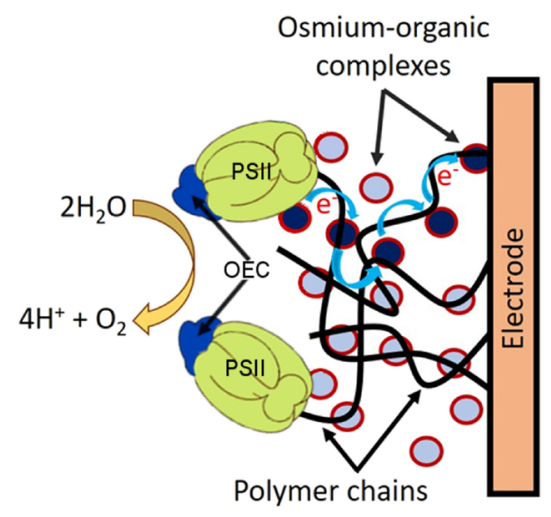

Fig. 4. An example of hybrid electrode design based on PSII complexes immobilized on a conductive substrate by a polymer gel layer containing redox agents. Adapted from Badura et al. (2008).

There are many different kinds of hybrid electrodes. However, it is impossible for now to choose the best one. There are no standard conditions for the hybrid photoelectrode activity measurement (Musazade et al. 2018).

\section{PSII in solar-to-electricity convertors}

Artificial solar-to-electricity converters are called photoelements or solar cells (Allakhverdiev et al. 2010b). Sometimes the terms 'photovoltaic cell' or 'photogalvanic cell' are also used (Kostic 2007, Gangotri and Bhimwal 2011). Ecological and economical obstacles of the conventional semiconductor solar cells force the scientist to design, build, and test novel devices to convert solar energy. One of the directions in this field is the incorporation of the biological pigment-protein complexes into solar cell devices. Solar cells containing pigment-protein complexes are called biohybrid solar cells (Musazade et al. 2018). We will use the term 'photo-bioelectrochemical cells' or PBEC. This more common term includes both photohydrogen production and photocurrent-generation devices (Rasmussen and Minteer 2014, Plumeré and Nowaczyk 2016, Yehezkeli et al. 2016, Wey et al. 2019). It is worth noting that researchers have not yet come to a standard for terminology in this field.

\section{PBEC structure}

A typical PBEC consists of a hybrid photoanode, an electrolyte, and a cathode. The photoanode is a conductive or semi-conductive substrate that is sensitized by components of the photosynthetic apparatus. The cathode is also a conductive inorganic electrode. In some cases, the cathode can be functionalized with a catalyst of a biological or artificial nature. Platinum is the most common catalyst used at the cathode (Rao et al. 1990, Lukashev et al. 2007, Ihssen et al. 2014, Pinhassi et al. 2016). The main function of a cathode catalyst is to accelerate reduction reactions and/or to participate in the 
synthesis of molecular fuels such as molecular hydrogen. In the latter case, the main product of the cell is not electricity but hydrogen (Barber and Tran 2013). The electrolyte transfers charge between the cathode and the photoanode sensitized by the photosystems. If such a cell is connected to an external circuit, it can generate a current under the influence of light. Light causes charge separation in the $\mathrm{RC}$ and photoelectrons from the $\mathrm{RC}$ migrate through the cofactor chain to the anode (Fig. 5). $\mathrm{RC}$ is recovered by electrons from electrolyte charge carriers, which, in turn, receive electrons from the cathode (Musazade et al. 2018). Some electrochemical cells implement a cathodic current: the RC donates an electron to a solubilized electronic mediator and accepts electrons from the electrode on which it is immobilized (Trammell et al. 2004, Yehezkeli et al. 2013).

\section{Efficiency assessment for PBEC}

The efficiency of the light energy conversion in biohybrid solar cells can be determined by distinct ways: conventional ratio of the electric power to the light power, external quantum efficiency, turnover frequency of immobilized RC. Any solar cell in addition to the efficiency terms can be described by three voltammetric parameters: shortcircuit current $\left(\mathrm{I}_{\mathrm{sc}}\right)$, open-circuit voltage $\left(\mathrm{V}_{\mathrm{oc}}\right)$, and fill factor (FF) (Pandey et al. 2016). $\mathrm{I}_{\mathrm{sc}}$ is the current value for the circuit with a vanishingly low resistance of the load. In the short circuit, mode voltage is equal to zero. $\mathrm{V}_{\mathrm{oc}}$ is the voltage on the circuit with very high resistance to the load. In the open circuit mode, there is no current flow through the chain. In some reports about biohybrid solar cells, only short-circuit current or short-circuit

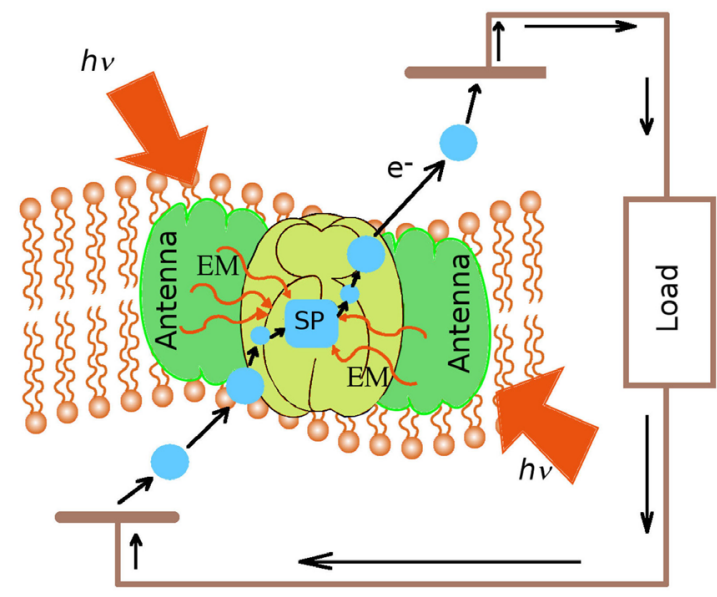

Fig. 5. The general principle of PBEC operation: light excites the antenna complexes which activates the transfer of energy through the inductive-resonant mechanism to the special pair (SP) of $\mathrm{RC}$; charge separation occurs in $\mathrm{RC}$; the electron is transferred through a series of carriers to the electrode and further into the external circuit; recovery of RC electrodes occurs at the expense of the second electrode. RC - reaction center. Adapted from Musazade et al. (2018). current density is presented as a single characteristic of the cell (Kavadiya et al. 2016, Voloshin et al. 2019). Unfortunately, effectiveness depends not only on the short-circuit current. It can be calculated from the data of the I-V curve (Voloshin et al. 2016). Quantum yield (external quantum efficiency, EQE) is another useful physical quantity for evaluating efficiency. It is a more powerful quantity for spectral analysis. EQE is determined as the ratio of the number of generated photoelectrons by cell per second to the number of incident light quantum under monochromatic illumination. In contrast, internal quantum efficiency (IQE) is the ratio of the photoelectrons generated to the number of photons absorbed. For the same device and light conditions, IQE is higher than EQE (Pratiyush et al. 2018). IQE is more complicated for calculation than EQE. The above-mentioned methods of calculation are suitable for the comparison of solar cells. If one would like to compare the functionality of the RC immobilized into the cell with native $\mathrm{RC}$, the turnover frequency or turnover number values should be exploited (Friebe and Frese 2017).

The efficiency of the PBEC depends on many factors, including the design of the developed electrode, the materials used, the methods of immobilization of the photosystem complexes, and measuring conditions. There are many works on the analysis of hybrid electrodes using a three-electrode scheme (Zhang and Reisner 2020). This scheme allows a bias voltage to be applied to the working electrode. In this scheme, the hybrid working photoelectrode consumes external energy, and the efficiency of photocurrent generation is not the efficiency of the electrode. In general, analytical three-electrode cells are not PBECs designed for energy conversion.

\section{Overview of the PSII-based PBEC}

The considered features of PSII-based cells contribute to the final efficiency of the PBEC. They affect the efficiency of light photon energy absorption by pigments, charge separation in $\mathrm{RC}$, and transfer of electrons from $\mathrm{RC}$ to the electrode, diffusion of electrons in the electrode and ions in the electrolyte, as well as reduction of oxidized $\mathrm{RC}$ pigments. There are many different types of biohybrid solar cells, based on the photosynthetic RCs. They are distinct by the source of the RC, materials of the electrodes, immobilization techniques, constructions of the whole cell.

There are no standard conventional light conditions for the laboratory solar cell testing and a typical form for the presentation of results. This leads to difficulties in the scientific literature analysis (Voloshin et al. 2017). Despite this problem, we summarize the most interesting results for the biohybrid solar cells based on the PSII and present them in Table 1. However, since not all works report the efficiency of the PBEC, we compared these cells by the values of the photocurrent density.

According to the data presented in Table 1, we can conclude that among the presented substrate materials and immobilization methods, the least effective is the combination of an ITO substrate with PSII adsorption 
Table 1. The PSII PBEC efficiencies are based on generated photocurrent densities. J - photocurrent density; ITO - indium tin oxide; DCBQ - 2,6-dichloro-1,4-benzoquinone; SAM - self-assembling monolayer; IO-mesoITO - hierarchically structured inverse opal mesoporous indium tin oxide. ${ }^{*}-$ no applied bias.

\begin{tabular}{|c|c|c|c|c|c|c|}
\hline & $\begin{array}{l}\text { Pigment-protein } \\
\text { complex }\end{array}$ & $\begin{array}{l}\text { Working electrodes } \\
\text { material }\end{array}$ & Light conditions & $\begin{array}{l}\text { Light intensity } \\
{\left[\mathrm{mW} \mathrm{cm}^{-2}\right]}\end{array}$ & $\mathrm{J}\left[\mu \mathrm{A} \mathrm{cm}^{-2}\right]$ & Reference \\
\hline 1 & $\begin{array}{l}\text { PSII from } \\
\text { T. elongatus }\end{array}$ & $\begin{array}{l}\text { Smooth } \mathrm{Au} \mid \mathrm{Os} \\
\text { redox polymer } \mid \text { PSII }\end{array}$ & $\begin{array}{l}\text { Halogen lamp using } \\
\text { a } 675 \text {-nm interference filter } \\
\text { and a cold light filter }\end{array}$ & 2.65 & 45 & $\begin{array}{l}\text { Badura et al. } \\
(2008)\end{array}$ \\
\hline 2 & $\begin{array}{l}\text { PSII from } \\
\text { T. elongatus }\end{array}$ & Mesoporous ITO | SAM | PSII & $\begin{array}{l}\text { Red light irradiation, } \\
679 \mathrm{~nm}\end{array}$ & 10 & 4.5 & $\begin{array}{l}\text { Kato et al. } \\
\text { (2013) }\end{array}$ \\
\hline 3 & $\begin{array}{l}\text { PSII core particles from } \\
\text { T. elongatus BP-1 }\end{array}$ & $\begin{array}{l}\text { IO-mesoITO | PSII } \\
\text { (mediated by DCBQ) }\end{array}$ & $\begin{array}{l}\text { Halogen lamp, band-pass } \\
\text { filter, } 679 \mathrm{~nm} \text {, red light }\end{array}$ & 10 & 930 & $\begin{array}{l}\text { Mersch et al. } \\
\text { (2015) }\end{array}$ \\
\hline 5 & $\begin{array}{l}\text { PSII core particles from } \\
\text { T. elongatus BP-1 }\end{array}$ & $\begin{array}{l}\mathrm{ITO}\left|\mathrm{TiO}_{2}\right| \mathrm{PSII} \\
\text { (mediated by DCBQ) }\end{array}$ & $\begin{array}{l}\text { Xenon lamp, } 590 \mathrm{~nm} \\
\text { cut-off filter, red light }\end{array}$ & $\begin{array}{l}<10 \\
\left(800 \mu \mathrm{E} \mathrm{m}^{-2} \mathrm{~s}^{-1}\right)\end{array}$ & 1.2 & $\begin{array}{l}\text { Brinkert et al. } \\
\text { (2016) }\end{array}$ \\
\hline 6 & PSII from spinach & $\begin{array}{l}\text { Macroporous carbon | } \\
\text { polyethylenimine | PSII } \\
\text { (mediated by DCBQ) }\end{array}$ & Solar light simulator AM 1.5 & 80 & $7.7^{*}$ & $\begin{array}{l}\text { Tian et al. } \\
(2021)\end{array}$ \\
\hline 7 & PSII from spinach & $\begin{array}{l}\text { ITO }\left|\mathrm{TiO}_{2}\right| \text { bio-nano-coctail } \\
\text { (PSII-ruthenium complexes) }\end{array}$ & Solar light simulator AM 1.5 & 100 & $888^{*}$ & $\begin{array}{l}\text { Güzel et al. } \\
(2020)\end{array}$ \\
\hline
\end{tabular}

on titanium dioxide (Table 1, entry 1). The authors of the study associate it with ineffective electron transfer from PSII to titanium dioxide (Brinkert et al. 2016).

In addition, the use of SAM for immobilization of PSII (Table 1, entry 2) is also not very effective due to an energy barrier located on SAM for an electron transported from $\mathrm{RC}$ to a conducting substrate (Trammell et al. 2006, Kato et al. 2013). In this regard, the methods for immobilizing PSII, which provide the closest possible contact of RC with a conducting substrate, are preferable (den Hollander et al. 2011).

The photocurrent densities of PBEC based on PSII do not differ much on flat gold substrates using a histidine strand and osmium-modified redox polymer (Table 1, entries 3 and 4). Thus, complex modifications of PSII required for the construction of a hybrid electrode with $\mathrm{Au} \mid$ histidine-tagged PSII appears to be unattractive.

As the results shown in entries 5 and 6 of Table 1 and obtained under similar conditions, it is observed that the current density in PBEC based on PSII using osmium-modified redox polymer is about half that generated by PBEC based on core complexes without this polymer. Possibly, this is due to the smaller size of the core complexes as compared to the whole PSII, which affects the ability of the former to penetrate deeper into the structure of the conducting substrate and thereby ensure the immobilization of a larger amount of RC on the substrate (Mersch et al. 2015, Sokol et al. 2016).

Entry 7 (Table 1) demonstrates the most intriguing results obtained by Güzel et al. (2020). They made dye-sensitized solar cells with PSII-bio-nano-coctail that served as a dye. A sufficiently high photocurrent was generated without any external bias. Unfortunately, it is unclear whether the main contribution to the photocurrent comes from ruthenium dye or PSII.

The data shown in Table 1 indicate that the most efficient generation of photocurrent occurs in PSII-based
PBECs using mesostructured materials that enable a larger number of RCs to be absorbed.

\section{PSII in solar-to-hydrogen convertors}

Molecular hydrogen is a high-energy, clean, and renewable fuel (Babu et al. 2012). However, conventional production processes for $\mathrm{H}_{2}$ require significant improvement in efficiencies, reduced capital costs, enhanced reliability, and operating flexibility (Allakhverdiev et al. 2009). $\mathrm{H}_{2}$ synthesis needs proton, energy, and catalyst.

Water is a ubiquitous source of protons and PSII is a native complex that can use sunlight for water splitting into the protons and oxygen. So, PSII can take part in one of two half-reactions for hydrogen production in PBEC (Fig. 6). The main principle of this PBEC operation is to separate in space water-splitting process and $\mathrm{H}_{2}$ synthesis reaction. PSII-based hybrid photoelectrode can be utilized in the first process proceeding in the anodic chamber. Hydrogen synthesis occurs in the cathodic chamber on the catalytic cathode. These reactions are connected in two ways. The first way is the electrical current through the external circuit. The second way is the migration of protons through the proton exchange membrane (PEM) to the cathodic chamber.

Platinum is the most common catalyst for proton reduction and can be used in tandem with photosynthetic apparatus components ( $\mathrm{Li}$ et al. 2017). However, platinum is an expensive noble metal. One of the alternatives to $\mathrm{Pt}$ is native enzyme hydrogenase that can reduce protons and produce the hydrogen. In this case, the design of the hydrogenase cathode is an additional challenge. As in the case of PSII-electrodes, the IO-mesoITO electrodes are a contemporary solution for this issue (Mersch et al. 2015).

Another problem is related to the energy mismatch between the terminal electron acceptor inside PSII and 


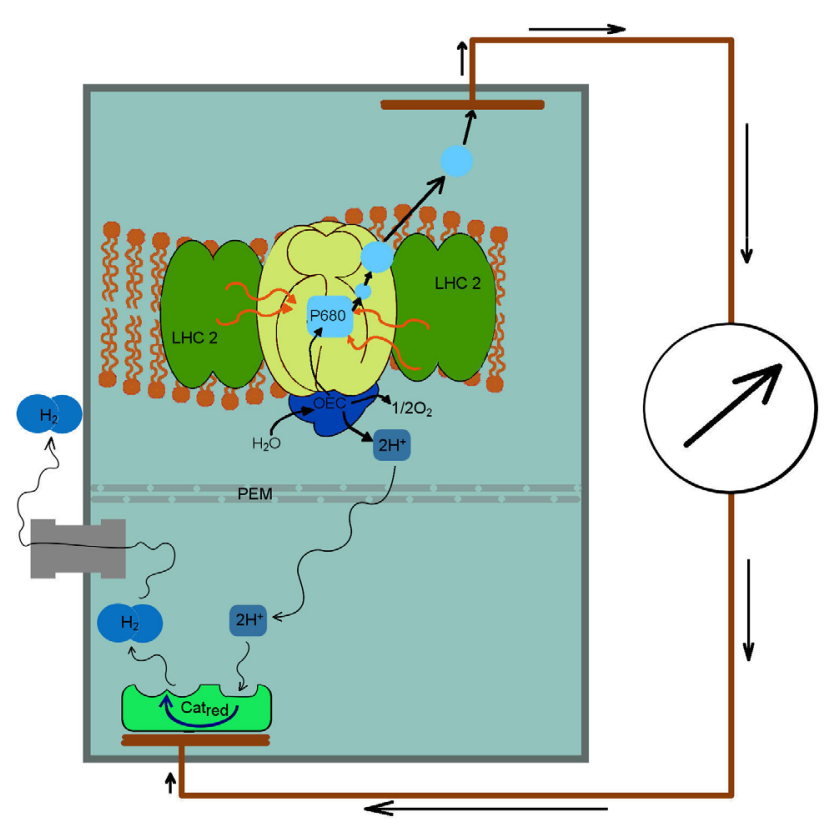

Fig. 6. The general principle of the hydrogen-producing PBEC. LHC - light-harvesting complex; OEC - oxygen-evolving complex; PEM - proton exchange membrane; $\mathrm{Cat}_{\text {red }}$ - reduction catalyst responsible for the $\mathrm{H}_{2}$ synthesis. The platinum or hydrogenase can serve as $\mathrm{Cat}_{\mathrm{red}}$. The arrow in the circle on the right indicates a potentiostat that can bias the electrodes.

the $\mathrm{Fe}-\mathrm{S}$ cluster inside hydrogenase (Zhang and Reisner 2020). A simple solution is to apply bias to the working electrode. Such a version is depicted in Fig. 6. However, more interesting solution is to use a second photocatalyst, in an analogy similar to the native photosynthesis. It can be PSI, photoactive semiconductor, or artificial dye (Mersch et al. 2015, Li et al. 2017, Zhang and Reisner 2020). This method will avoid unnecessary energy consumption for fuel production.

The term 'semi-artificial photosynthesis' is used for research direction on the solar-fuel and solar-chemical pathways in the hybrid system incorporating artificial components with native enzymes, pigment proteincomplexes, or whole cells (Kornienko et al. 2018). Comprehensive reviews describe semi-artificial photosynthetic systems based on whole cells (Kornienko et al. 2018) and isolated PSII complexes (Zhang and Reisner 2020).

\section{PSII in herbicide biosensors}

The majority of the herbicide used for chemical weeding are inhibitors of the photosynthetic activity (Carpentier et al. 1991). Due to this, the efficiency of the photoinduced electron transfer in the PSII-based hybrid device can be used for indication of the herbicide presence in the sample. For effective detection, a biosensor must have the following properties (Conrad et al. 1993, Giardi et al. 2001):
(1) Specificity. The sensor should allow determining the type of detected herbicides.

(2) Reproducibility. Results obtained by the sensor should be reproduced under the same conditions.

(3) Stability. The sensor should be reusable.

(4) Sensitivity. The limit of detection should be satisfactory low.

There are several ways to utilize PSII complexes for herbicide detection. They include the analysis of the Hill reaction inhibition ( $\mathrm{Li}$ et al. 2005), the analysis of the change in the fluorescent induction curve (Conrad et al. 1993), and the analysis of the photoelectric characteristics of the PSII-based hybrid electrode (Koblížek et al. 2002). Any biosensors require measurement of a calibration curve prior they are put into exploitation. The Langmuir adsorption isotherm is the generally accepted model for analyzing a calibration curve (Touloupakis et al. 2005, Masojídek et al. 2011).

The form of the induction curve of the chlorophyll fluorescence in PSII preparation is directly related to the photosynthetic activity of the PSII. This fact underlies the fluorimetry techniques of the photosynthetic activity assay (Lavergne and Trissl 1995, Schansker et al. 2011). At the moment, there are many special devices for measuring the induction curve and deeply developed interpretation protocols for analyzing this curve (Stirbet and Govindjee 2011, Kalaji et al. 2014, 2017; Stirbet et al. 2018). The herbicides inhibiting photosynthesis also affect the induction fluorescence curve (Bukhov et al. 2004). A powerful technique to interpret the change in the fluorescence induction curve allows using fluorescent PSII-based biosensor for the herbicide detection. The fluorescent biosensors can be distinguished into two types. The first type uses green algae as a sensing element (Conrad et al. 1993, Antonacci et al. 2021). The second type uses isolated photosynthetic membranes or PSII complex preparation (Merz et al. 1996, Giardi et al. 2005). In both types, the fluorescence signal from PSII is detected. It is worth noting that in older works, the sensitive element of the sensor was a suspension of the membrane preparation or algae cells (Conrad et al. 1993, Merz et al. 1996). In more recent works, the sensitive element was immobilized (Giardi et al. 2005, Antonacci et al. 2021). Giardi et al. (2005) used bovine serum albumin (BSA)-glutaraldehyde matrix and $\mathrm{CdCl}_{2}$ matrix for immobilization. In that work, a scheme of the whole sensor system with four flow sensor cells is presented. The results of the test of this system with the river water samples were also presented. The use of both a PSII preparation from wild-type plants and mutant species resistant to atrazine in one iteration of the analysis of a sample allows the sensor to distinguish between different types of herbicides (Giardi et al. 2005). The work of Antonacci et al. (2021) is notable for the sensor design allowing simultaneous recording of fluorescence and electricity signals. Algal cells in that work were immobilized onto the paper-based screenprinted electrodes nanomodified with carbon black. A disadvantage of the fluorescent sensor is its complicated 
structure: the sensor should include a sample chamber, source of the light, and fluorescence signal detector.

Photovoltaic PSII-based biosensor does not include fluorescence light detector. It contains PSII-based electrodes like those in the PBEC. However, in the biosensor, this electrode immersed into the sample solution should be exposed to the stable red light for reusable herbicide detection (Fig. 7).

Electricity signals generated by the same electrodes under the same light conditions will be affected only by herbicide inhibitory activity. There are several works with PSII-based electrodes designed by screen-printed methods (Koblížek et al. 2002, Malý et al. 2005a, Bettazzi et al. 2007, Masojídek et al. 2011). Screen printing is a relatively simple procedure for electrode system preparation. It consists of the transferring of the layout onto a substrate through the open mesh of a screen (Touloupakis et al. 2005). Polyvinyl chloride (PVC) is a frequently used substrate material. This technique allows the anode and cathode to be fixed on the same flat substrate. This flat two-electrode system is very useful for portable sensor devices. This technique allows preparing of either twoelectrode or three-electrode schemes onto the flat substrate (Koblížek et al. 2002, Malý et al. 2005a, Touloupakis et al. 2005). Touloupakis et al. (2005) built a sensor based on the spinach thylakoids with a half-life of about $17 \mathrm{~h}$ and a limit of detection of about $10^{-8} \mathrm{M}$ for diuron, atrazine, simazine, and several other herbicides. They used the BSA-glutaraldehyde matrix for membrane immobilization and duroquinone as an exogenic mediator. After each measurement, the biosensor had to be rinsed by buffer with mediators. This sensor was tested on herbicide detection in river water (Touloupakis et al. 2005). At the working electrode, PSII-containing membranes immobilized into glutaraldehyde matrix were deposited onto the carbon electrode. Using another PSII-based biosensor, Malý et al. (2005a) measured the stability of isoproturon at different soil depths. PSII-based biosensors are promising probes for specific and rapid detection of herbicides.

\section{$\mathrm{H}_{2}$ photoproduction in the systems mimicking PSII}

The concept of semi-artificial photosynthesis embrace systems for fuel synthesis cost by the light that should overcome the limitations of natural enzyme complexes and fully man-made systems (Kornienko et al. 2018). However, the main challenge of the natural system - its low stability - is rather difficult to solve. For now, the most longevous PSII-based electrode allowed the stable output for $5 \mathrm{~d}$ (Tian et al. 2021). Design of the fully artificial system that mimics the process that occurred in the native photosystem is an actively developed area. The scheme of such system aimed at hydrogen production is depicted in Fig. 8. Like a PBEC in Fig. 6, it includes two parts: donor part and acceptor part. Water oxidation on the donor part provides electrons for the reduction of protons that occurs on the acceptor part.

The main three components of the artificial photosynthesis system include photosensitizer, water-splitting catalyst, and proton-reduction catalyst. It is believed that artificial photosynthesis began to develop thanks to the work of Fujishima and Honda (1972), who observed UV-induced decomposition of water into protons and oxygen in titanium dioxide (Fujishima and Honda 1972, Barber and Tran 2013). Since then, the photocatalytic properties of semiconductors, both pure and sensitized with synthetic dyes, have been actively studied. The most popular semiconductor in this field has been titanium dioxide. However, pure $\mathrm{TiO}_{2}$ has some disadvantages that can be eliminated by several additives.

Combining tungsten oxide $\left(\mathrm{WO}_{3}\right)$ semiconductor nanomaterials with the Mn-oxo catalyst as a PBEC system can overcome a key challenge in using semiconductors directly, which is the low catalytic activity of semiconductors. For example, the surface of $\mathrm{WO}_{3}$ semiconductor may be coated with the Mn-oxo oligomer catalyst by thermal treatment of a solution of the Mn-oxo dimer compound (Liu et al. 2011). The preparation took typically $5 \mathrm{~min}$ and did not cause noticeable colorization of $\mathrm{WO}_{3}$. Deposition of the Mn catalyst is preferred for at least three reasons: (1) deposition is straightforward, (2) the coating does not compete with $\mathrm{WO}_{3}$ in light absorption, and (3) the catalyst facilitates hole transfer from the semiconductor to the solution. The working hypothesis is similar to PSII. The light radiation is absorbed by the $\mathrm{WO}_{3}$ semiconductor as $\mathrm{P}_{680}$ in PSII and causes a charge separation to produce electrons and holes. The electrons may be transferred to the cathode by an electric wire to
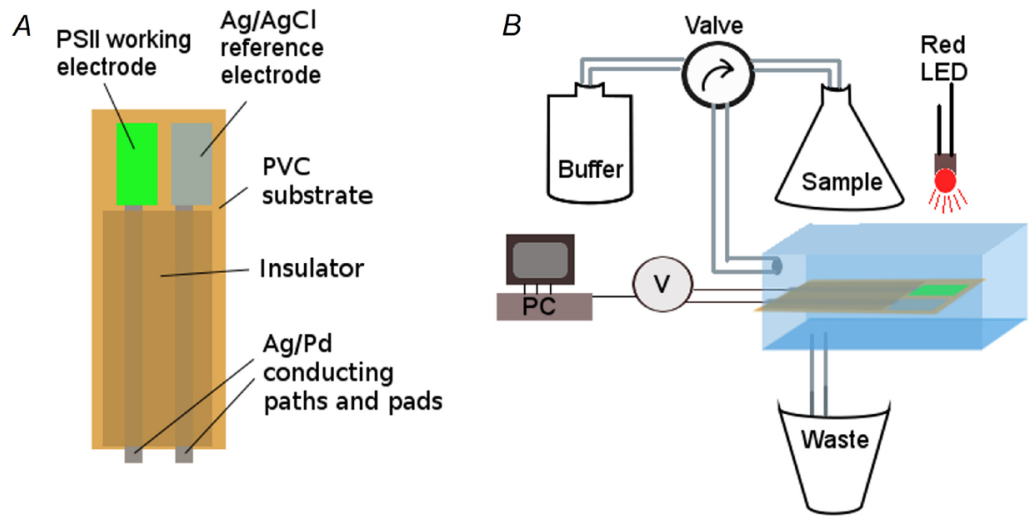

Fig. 7. Biosensing chip based on the twoelectrode scheme $(A)$. Simplified scheme of the whole sensing system $(B)$. PVC - polyvinyl chloride; V - voltmeter. Adopted from Koblížek et al. (2002) and Touloupakis et al. (2005). 


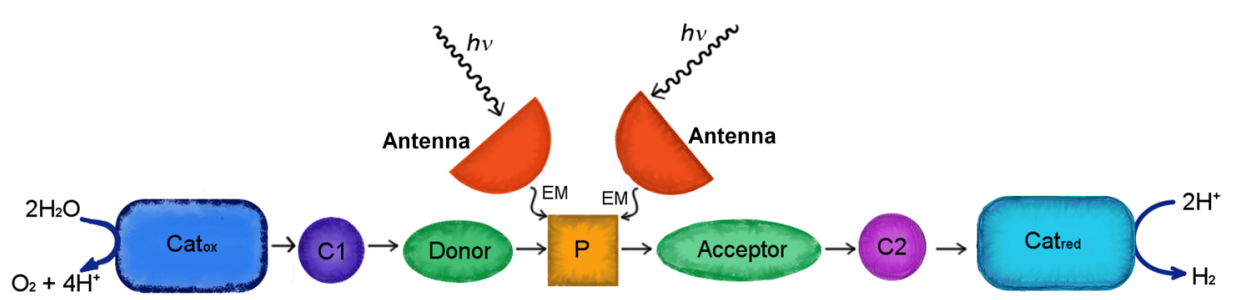

Fig. 8. Scheme of the artificial photosystem. Cat red $_{\text {- catalyst }}$ for chemical $\mathrm{H}_{2}$ reduction, $\mathrm{Cat}_{\mathrm{ox}}$ - catalyst for chemical water oxidation; $\mathrm{C} 1$ and $\mathrm{C} 2$ electron carriers on the donor and acceptor parts; $\mathrm{P}$ photosensitizer. Adapted from Allakhverdiev et al. (2010a). produce hydrogen gas in a photoelectrochemical cell. Donating electrons to the holes, the Mn-oxo oligomer can extract electrons from water to evolve molecular oxygen following the catalytic mechanism described (Chou et al. 2012).

Artificial photosynthesis is not limited by photoinduced water splitting. There are many variants of hydrogen synthesis catalysts and photosensibilizators based on the ruthenium complexes or quantum dots. Allakhverdiev et al. (2010a) and McConnell et al. (2010) have presented comprehensive reviews on artificial photosynthesis for hydrogen production.

Conclusion: The water-splitting reaction in PSII driven by sunlight in plants, algae, and cyanobacteria stores a vast amount of solar energy and provides vital oxygen to life on the Earth. The use of PSII holds promise in several applications. Unfortunately, the photocurrent signal received from the PSII electrodes is very weak and, in many cases, requires external bias. At the same time, there are many prospects for the development of various hybrid electrodes. Reisner's group is actively developing inverse opal IO-mesoITO electrodes with a hierarchical structure and has high hopes for them (Mersch et al. 2015, Sokol et al. 2016, Zhang et al. 2016). At the moment, this kind of PSII-based electrode seems to generate the highest photoelectric signals. IO-mesoITO electrodes can be used also for hydrogenase immobilization. Mersch et al. (2015) demonstrated the production of photohydrogen with $5.4 \%$ efficiency in a PBEC combining IO-mesoITO | PSII photoanode and IO-mesoITO | hydrogenase cathode. Another interesting topic requiring further development is the synthesis of PSII-bio-nanococtail. Güzel et al. (2020) suggest that PSII complexes in such bio-nano-cocktails will be more stable.

To date, there are no examples of PBEC based on bRC fixed on IO-mesoITO substrates in the literature; however, considering the efficiency of such design of electrodes with PSII, similar PBECs based on bRC will probably also show the high efficiency of photocurrent generation (Friebe and Frese 2017). The efficiency of solar cells based on bacterial RC may be even higher since the RC has a smaller size and can penetrate the channels of the mesoporous substrate.

In the herbicide photo-bioelectrochemical sensor area, research in recent years has been focusing on the use of the whole photosynthetic organisms instead of isolated PSII complexes (Tucci et al. 2019, Antonacci et al. 2021). There are many achievements in artificial photosynthesis for now. We have seen significant progress in photoelectrochemical water splitting using Mn-oxo complexes and Co-based molecular catalysts (Dogutan and Nocera 2019, He et al.2019, Spies et al. 2019, Hou 2021). In particular, the $\mathrm{Mn} / \mathrm{Nafion}, \mathrm{Mn} / \mathrm{TiO}_{2}, \mathrm{Mn} / \mathrm{WO}_{3}$, $\mathrm{Co} / \mathrm{Fe}_{2} \mathrm{O}_{3}, \mathrm{Co} / \mathrm{ZnO}$ systems developed may be extended to heterostructures of a variety of semiconductors (He et al. 2019, Spies et al. 2019, Hou 2021). The protocols are suited for preparing earth-abundant metal/ semiconductor catalysts.

Semi-artificial and artificial photosynthesis must be developed side by side. Identifying the processes occurring at the enzyme/electrode interface should provide more inspiration and information for creating an artificial stable system.

\section{References}

Allakhverdiev S.I., Kreslavski V.D. Thavasi V. et al.: Hydrogen photoproduction by use of photosynthetic organisms and biomimetic systems. - Photoch. Photobio. Sci. 8: 148-156, 2009.

Allakhverdiev S.I., Kreslavski V., Thavasi V. et al.: Photosynthetic energy conversion: Hydrogen photoproduction by natural and biomimetic means. - In: Mukherjee A. (ed.): Biomimetics Learning from Nature. Pp. 49-75. InTech 2010a.

Allakhverdiev S.I., Thavasi V., Kreslavski V.D. et al.: Photosynthetic hydrogen production. - J. Photoch. Photobio. C 11: 101-113, 2010b.

Allen M.J.: Direct conversion of radiant into electrical energy using plant systems. - In: Buvet R., Allen M.J., Massué J.-P. (ed.): Living Systems As Energy Converters. Proceedings of the European Conference on Living Systems as Energy Converters. Pp. 271-274. Elsevier 1977.

Antonacci A., Attaallah R., Arduini F. et al.: A dual electro-optical biosensor based on Chlamydomonas reinhardtii immobilised on paper-based nanomodified screen-printed electrodes for herbicide monitoring. - J. Nanobiotechnology 19: 145, 2021.

Babu V.J., Kumar M.K., Nair A.S. et al.: Visible light photocatalytic water splitting for hydrogen production from $\mathrm{N}-\mathrm{TiO}_{2}$ rice grain shaped electrospun nanostructures. - Int. J. Hydrogen Energ. 37: 8897-8904, 2012.

Badura A., Guschin D., Esper B. et al.: Photo-induced electron transfer between photosystem 2 via cross-linked redox hydrogels. - Electroanalysis 20: 1043-1047, 2008.

Barber J., Tran P.D.: From natural to artificial photosynthesis. J. R. Soc. Interface 10: 20120984, 2013.

Bettazzi F., Laschi S., Mascini M.: One-shot screen-printed thylakoid membrane-based biosensor for the detection of photosynthetic inhibitors in discrete samples. - Anal. Chim. Acta 589: 14-21, 2007.

Brinkert K., Le Formal F., Li X. et al.: Photocurrents from photosystem II in a metal oxide hybrid system: Electron transfer pathways. - BBA-Bioenergetics 1857: 1497-1505, 2016. 
Bukhov N.G., Egorova E.A., Govindachary S., Carpentier R.: Changes in polyphasic chlorophyll $a$ fluorescence induction curve upon inhibition of donor or acceptor side of photosystem II in isolated thylakoids. - BBA-Bioenergetics 1657 : 121-130, 2004.

Carpentier R., Loranger C., Chartrand J., Purcell M.: Photoelectrochemical cell containing chloroplast membranes as a biosensor for phytotoxicity measurement. - Anal. Chim. Acta 249: 55-60, 1991.

Chen H., Blaber M.G., Standridge S.D. et al.: Computational modeling of plasmon-enhanced light absorption in a multicomponent dye sensitized solar cell. - J. Phys. Chem. C 116: 10215-10221, 2012.

Chou L.Y., Liu R., He W. et al.: Direct oxygen and hydrogen production by photo water splitting using a robust bioinspired manganese-oxo oligomer complex/tungsten oxide catalytic system. - Int. J. Hydrogen Energ. 37: 8889-8896, 2012.

Conrad R., Büchel C., Wilhelm C. et al.: Changes in yield of in-vivo fluorescence of chlorophyll a as a tool for selective herbicide monitoring. - J. Appl. Phycol. 5: 505-516, 1993.

Cox N., Messinger J.: Reflections on substrate water and dioxygen formation. - BBA-Bioenergetics 1827: 1020-1030, 2013.

Dankov K., Rashkov G., Misra A.N., Apostolova E.L.: Temperature sensitivity of photosystem II in isolated thylakoid membranes from fluridone-treated pea leaves. - Turk. J. Bot. 39: 420-428, 2015.

den Hollander M.J., Magis J.G., Fuchsenberger P. et al.: Enhanced photocurrent generation by photosynthetic bacterial reaction centers through molecular relays, light-harvesting complexes, and direct protein-gold interactions. - Langmuir 27: 1028210294, 2011.

Dogutan D.K., Nocera D.G.: Artificial photosynthesis at efficiencies greatly exceeding that of natural photosynthesis. Acc. Chem. Res. 52: 3143-3148, 2019.

Drachev L.A., Kondrashin A.A., Samuilov V.D., Skulachev V.P.: Generation of electric potential by reaction center complexes from Rhodospirillum rubrum. - FEBS Lett. 50: 219-222, 1975.

Emerson R., Chalmers R., Cederstrand C.: Some factors influencing the long-wave limit of photosynthesis. - P. Natl. Acad. Sci. USA 43: 133-143, 1957.

Faulkner C.J., Lees S., Ciesielski P.N. et al.: Rapid assembly of photosystem I monolayers on gold electrodes. - Langmuir 24: 8409-8412, 2008.

Faure B., Salazar-Alvarez G., Ahniyaz A. et al:: Dispersion and surface functionalization of oxide nanoparticles for transparent photocatalytic and UV-protecting coatings and sunscreens. - Sci. Technol. Adv. Mater. 14: 023001, 2013.

Frenzel M., Hirsch T., Gutzmer J.: Gallium, germanium, indium, and other trace and minor elements in sphalerite as a function of deposit type - A meta-analysis. - Ore Geol. Rev. 76: 52-78, 2016.

Friebe V.M., Frese R.N.: Photosynthetic reaction center-based biophotovoltaics. - Curr. Opin. Electrochem. 5: 126-134, 2017.

Friebe V.M., Millo D., Swainsbury D.J.K. et al.: Cytochrome $c$ provides an electron-funneling antenna for efficient photocurrent generation in a reaction center biophotocathode. ACS Appl. Mater. Interfaces 9: 23379-23388, 2017.

Frolov L., Rosenwaks Y., Carmeli C., Carmeli I.: Fabrication of a photoelectronic device by direct chemical binding of the photosynthetic reaction center protein to metal surfaces. Adv. Mater. 17: 2434-2437, 2005.

$\mathrm{Fu}$ H.-Y., Picot D., Choquet Y. et al.: Redesigning the $\mathrm{Q}_{\mathrm{A}}$ binding site of Photosystem II allows reduction of exogenous quinones. - Nat. Commun. 8: 15274, 2017.

Fujishima A., Honda K.: Electrochemical photolysis of water at a semiconductor electrode. - Nature 238: 37-38, 1972.

Gall B., Zehetner A., Scherz A., Scheer H.: Modification of pigment composition in the isolated reaction center of photosystem II. - FEBS Lett. 434: 88-92, 1998.

Gangotri K.M., Bhimwal M.K.: The photochemical conversion of solar energy into electrical energy: Eosin-fructose system.Environ. Prog. Sustain. Energy 30: 493-499, 2011.

Giardi M.T., Guzzella L., Euzet P. et al.: Detection of herbicide subclasses by an optical multibiosensor based on an array of photosystem II mutants. - Environ. Sci. Technol. 39: 5378$5384,2005$.

Giardi M.T., Koblížek M., Masojídek J.: Photosystem II-based biosensors for the detection of pollutants. - Biosens. Bioelectron. 16: 1027-1033, 2001.

Gizzie E.A., Scott Niezgoda J., Robinson M.T. et al.: Photosystem I-polyaniline/ $\mathrm{TiO}_{2}$ solid-state solar cells: simple devices for biohybrid solar energy conversion. - Energy Environ. Sci. 8: 3572-3576, 2015.

Govindjee, Kern J.F., Messinger J., Whitmarsh J.: Photosystem II. - In: Encyclopedia of Life Sciences. Pp. 1-15. John Wiley \& Sons, Ltd, Chichester 2010.

Grätzel M.: Mesoporous oxide junctions and nanostructured solar cells. - Curr. Opin. Colloid Interface Sci. 4: 314-321, 1999.

Grätzel M.: Photoelectrochemical cells. - Nature 414: 338-344, 2001.

Grätzel M.: Photovoltaic and photoelectrochemical conversion of solar energy. - Philos. T. Roy. Soc. A 365: 993-1005, 2007.

Güzel R., Yediyıldız F., Ocak Y.S. et al.: Photosystem (PSII)based hybrid nanococktails for the fabrication of BIO-DSSC and photo-induced memory device. - J. Photoch. Photobio. A Chem. 401: 112743, 2020.

Hakala M., Rantamäki S., Puputti E.M. et al.: Photoinhibition of manganese enzymes: Insights into the mechanism of photosystem II photoinhibition. - J. Exp. Bot. 57: 1809-1816, 2006.

Hasan K., Grippo V., Sperling E. et al.: Evaluation of photocurrent generation from different photosynthetic organisms. ChemElectroChem 4: 412-417, 2017.

He Y., Hamann T., Wang D.: Thin film photoelectrodes for solar water splitting. - Chem. Soc. Rev. 48: 2182-2215, 2019.

Hou H.J.M.: Toward molecular mechanisms of solar water splitting in semiconductor/manganese materials and photosystem II. - In: Shen J.R., Satoh K., Allakhverdiev S.I. (ed.): Photosynthesis: Molecular Approaches to Solar Energy Conversion. Advances in Photosynthesis and Respiration (Including Bioenergy and Related Processes). Vol. 47. Pp. 105-129. Springer, Cham 2021.

IEA: World Energy Outlook 2019. IEA, Paris 2019.

Ihssen J., Braun A., Faccio G. et al.: Light harvesting proteins for solar fuel generation in bioengineered photoelectrochemical cells. - Curr. Protein Pept. Sci. 15: 374-384, 2014.

Kalaji H.M., Schansker G., Brestic M. et al.: Frequently asked questions about chlorophyll fluorescence, the sequel. Photosynth. Res. 132: 13-66, 2017.

Kalaji H.M., Schansker G., Ladle R.J. et al.: Frequently asked questions about in vivo chlorophyll fluorescence: Practical issues. - Photosynth. Res. 122: 121-158, 2014.

Kato M., Cardona T., Rutherford A.W., Reisner E.: Covalent immobilization of oriented photosystem II on a nanostructured electrode for solar water oxidation. - J. Am. Chem. Soc. 135: 10610-10613, 2013.

Kato M., Zhang J.Z., Paul N., Reisner E.: Protein film photoelectrochemistry of the water oxidation enzyme 
photosystem II. - Chem. Soc. Rev. 43: 6485-6497, 2014.

Kavadiya S., Chadha T.S., Liu H. et al.: Directed assembly of the thylakoid membrane on nanostructured $\mathrm{TiO}_{2}$ for a photoelectrochemical cell. - Nanoscale 8: 1868-1872, 2016.

Kavan L., O'Regan B., Kay A., Grätzel M.: Preparation of $\mathrm{TiO}_{2}$ (anatase) films on electrodes by anodic oxidative hydrolysis of $\mathrm{TiCl}_{3}$. - J. Electroanal. Chem. 346: 291-307, 1993.

Kiley P., Zhao X., Vaughn M. et al.: Self-assembling peptide detergents stabilize isolated photosystem I on a dry surface for an extended time. - PLoS Biol. 3: e230, 2005.

Koblížek M., Malý J., Masojídek J. et al.: A biosensor for the detection of triazine and phenylurea herbicides designed using Photosystem II coupled to a screen-printed electrode. Biotechnol. Bioeng. 78: 110-116, 2002.

Kornienko N., Zhang J.Z., Sakimoto K.K. et al.: Interfacing nature's catalytic machinery with synthetic materials for semi-artificial photosynthesis. - Nat. Nanotechnol. 13: 890899, 2018.

Kostic M.M.: Energy : Global and Historical Background. - In: Capehart B.L. (ed.): Encyclopedia of Energy Engeneering. Pp. 1-15. Taylor \& Francis/Marcel Dekker 2007.

Kothe T., Plumeré N., Badura A. et al.: Combination of a photosystem 1-based photocathode and a photosystem 2-based photoanode to a Z-scheme mimic for biophotovoltaic applications. - Angew. Chem. Int. Ed. 52: 14233-14236, 2013.

Kumar P., Kuppam C. (eds.): Bioelectrochemical Systems. Pp. 326. Springer Singapore, Singapore 2020.

Lavergne J., Trissl H.W.: Theory of fluorescence induction in photosystem II: derivation of analytical expressions in a model including exciton-radical-pair equilibrium and restricted energy transfer between photosynthetic units. - Biophys. J. 68: 2474-2492, 1995.

Lebedev N., Trammell S.A., Spano A. et al.: Conductive wiring of immobilized photosynthetic reaction center to electrode by cytochrome c. - J. Am. Chem. Soc. 128: 12044-12045, 2006.

Lewis N.S., Nocera D.G.: Powering the planet: chemical challenges in solar energy utilization. - P. Natl. Acad. Sci. USA 103: 15729-15735, 2006.

Li J., Wei X., Peng T.: Fabrication of herbicide biosensors based on the inhibition of enzyme activity that catalyzes the scavenging of hydrogen peroxide in a thylakoid membrane. Anal. Sci. 21: 1217-1222, 2005.

Li Z., Wang W., Ding C. et al.: Biomimetic electron transport via multiredox shuttles from photosystem II to a photoelectrochemical cell for solar water splitting. - Energy Environ. Sci. 10: 765-771, 2017.

Liu R., Lin Y., Chou L.-Y. et al:: Water splitting by tungsten oxide prepared by atomic layer deposition and decorated with an oxygen-evolving catalyst. - Angew. Chem. Int. Ed. 50: 499-502, 2011.

Lu Y., Yuan M., Liu Y. et al.: Photoelectric performance of bacteria photosynthetic proteins entrapped on tailored mesoporous $\mathrm{WO}_{3}-\mathrm{TiO}_{2}$ films. - Langmuir 21: 4071-4076, $2005 \mathrm{a}$.

Lu Y.D., Liu Y., Xu J.J. et al.: Bio-nanocomposite photoelectrode composed of the bacteria photosynthetic reaction center entrapped on a nanocrystalline $\mathrm{TiO}_{2}$ matrix. - Sensors-Basel 5: 258-265, 2005b.

Lukashev E.P., Nadtochenko V.A., Permenova E.P. et al.: Electron phototransfer between photosynthetic reaction centers of the bacteria Rhodobacter sphaeroides and semiconductor mesoporous $\mathrm{TiO}_{2}$ films. - Dokl. Biochem. Biophys. 415: 211216, 2007.

Maksimov E.G., Lukashev E.P., Seifullina N.K. et al.: Photophysical properties of hybrid complexes of quantum dots and reaction centers of purple photosynthetic bacteria Rhodobacter sphaeroides adsorbed on crystalline mesoporous
TiO films. - Nanotechnol. Russ. 8: 423-431, 2013.

Malý J., Klem K., Lukavská A., Masojídek J.: Degradation and movement in soil of the herbicide isoproturon analyzed by a Photosystem II-based biosensor. - J. Environ. Qual. 34: 17801788, 2005a.

Malý J., Krejčí J., Ilie M. et al.: Monolayers of photosystem II on gold electrodes with enhanced sensor response - effect of porosity and protein layer arrangement. - Anal. Bioanal. Chem. 381: 1558-1567, 2005b.

Masojídek J., Souček P., Máchová J. et al:: Detection of photosynthetic herbicides: Algal growth inhibition test vs. electrochemical photosystem II biosensor. - Ecotox. Environ. Safe. 74: 117-122, 2011.

McConnell I., Li G., Brudvig G.W.: Energy conversion in natural and artificial photosynthesis. - Chem. Biol. 17: 434-447, 2010.

Mersch D., Lee C.Y., Zhang J.Z. et al.: Wiring of photosystem II to hydrogenase for photoelectrochemical water splitting. J. Am. Chem. Soc. 137: 8541-8549, 2015.

Mershin A., Matsumoto K., Kaiser L. et al.: Self-assembled photosystem-I biophotovoltaics on nanostructured $\mathrm{TiO}_{2}$ and ZnO. - Sci. Rep.-UK 2: 234, 2012.

Merz D., Geyer M., Moss D.A., Ache H.-J.: Chlorophyll fluorescence biosensor for the detection of herbicides. Fresenius J. Anal. Chem. 354: 299-305, 1996.

Michel H., Deisenhofer J.: Relevance of the photosynthetic reaction center from purple bacteria to the structure of photosystem II. - Biochemistry 27: 1-7, 1988.

Miyachi M., Ikehira S., Nishiori D. et al.: Photocurrent generation of reconstituted photosystem ii on a self-assembled gold film. - Langmuir 33: 1351-1358, 2017.

Müh F., Glöckner C., Hellmich J., Zouni A.: Light-induced quinone reduction in photosystem II. - BBA-Bioenergetics 1817: 44-65, 2012.

Musazade E., Voloshin R.A., Brady N. et al.: Biohybrid solar cells: Fundamentals, progress, and challenges. - J. Photoch. Photobio. C 35: 134-156, 2018.

Nelson N., Yocum C.F.: Structure and function of photosystems I and II. - Annu. Rev. Plant Biol. 57: 521-565, 2006.

Nguyen K., Bruce B.D.: Growing green electricity: Progress and strategies for use of Photosystem I for sustainable photovoltaic energy conversion. - BBA-Bioenergetics 1837: 1553-1566, 2014.

Nikandrov V.V., Borisova Y.V., Bocharov E.A. et al.: Photochemical properties of photosystem 1 immobilized in a mesoporous semiconductor matrix. - High Energy Chem. 46: 200-205, 2012.

Nisbet E.G., Grassineau N.V., Howe C.J. et al.: The age of Rubisco: The evolution of oxygenic photosynthesis. Geobiology 5: 311-335, 2007.

Nishiori D., Zhu W., Salles R. et al.: Photosensing system using photosystem I and gold nanoparticle on graphene field-effect transistor. - ACS Appl. Mater. Interfaces 11: 42773-42779, 2019.

Noji T., Suzuki H., Gotoh T. et al.: Photosystem II-gold nanoparticle conjugate as a nanodevice for the development of artificial light-driven water-splitting systems. - J. Phys. Chem. Lett. 2: 2448-2452, 2011.

Oshima T., Nishioka S., Kikuchi Y. et al.: An artificial Z-scheme constructed from dye-sensitized metal oxide nanosheets for visible light-driven overall water splitting. - J. Am. Chem. Soc. 142: 8412-8420, 2020.

Packham N.K., Packham C., Mueller P. et al.: Reconstitution de photochemically active reaction centers in planar phospholipid membranes. Light-induced electrical currents under voltageclamped conditions. - FEBS Lett. 110: 101-106, 1980. 
Pandey A.K., Tyagi V.V., Selvaraj J.A. et al.: Recent advances in solar photovoltaic systems for emerging trends and advanced applications. - Renew. Sust. Energ. Rev. 53: 859-884, 2016.

Pinhassi R.I., Kallmann D., Saper G. et al.: Hybrid bio-photoelectro-chemical cells for solar water splitting. - Nat. Commun. 7: 12552, 2016.

Plumeré N., Nowaczyk M.M.: Biophotoelectrochemistry of photosynthetic proteins. - In: Jeuken L. (ed.): Biophotoelectrochemistry: From Bioelectrochemistry to Biophotovoltaics. Advances in Biochemical Engineering/ Biotechnology. Vol. 158. Pp. 111-136. Springer, Cham 2016.

Pratiyush A.S., Krishnamoorthy S., Muralidharan R. et al.: Advances in $\mathrm{Ga}_{2} \mathrm{O}_{3}$ solar-blind UV photodetectors. - In: Pearton S., Ren F., Mastro M. (ed.): Gallium Oxide: Technology, Devices and Applications. Pp. 369-399. Elsevier, Amsterdam 2018.

Rao K.K., Hall D.O., Vlachopoulos N. et al.: Photoelectrochemical responses of photosystem II particles immobilized on dyederivatized $\mathrm{TiO}_{2}$ films. - J. Photoch. Photobio. B 5: 379-389, 1990.

Rasmussen M., Minteer S.D.: Photobioelectrochemistry: Solar energy conversion and biofuel production with photosynthetic catalysts. - J. Electrochem. Soc. 161: H647-H655, 2014.

Ridge Carter J., Baker D.R., Austin Witt T. et al:: Enhanced photocurrent from Photosystem I upon in vitro truncation of the antennae chlorophyll. - Photosynth. Res. 127: 161-170, 2016.

Rodionova M.V., Poudyal R.S., Tiwari I. et al.: Biofuel production: Challenges and opportunities. - Int. J. Hydrogen Energ. 42: 8450-8461, 2017.

Say R., Kılıç G.A., Özcan A.A. et al.: Bioconjugated and crosslinked bionanostructures for bifunctional immunohistochemical labeling. - Microsc. Microanal. 18: 324-330, 2012.

Schansker G., Tóth S.Z., Kovács L. et al.: Evidence for a fluorescence yield change driven by a light-induced conformational change within photosystem II during the fast chlorophyll $a$ fluorescence rise. - BBA-Bioenergetics 1807: 1032-1043, 2011.

Seibert M., Janzen A.F., Kendall-Tobias M.: Light-induced electron transport across semiconductor electrode/reactioncenter film/electrolyte interfaces. - Photochem. Photobiol. 35: 193-200, 1982

Shah V.B., Henson W.R., Chadha T.S. et al.: Linker-free deposition and adhesion of photosystem I onto nanostructured $\mathrm{TiO}$, for biohybrid photoelectrochemical cells. - Langmuir 31: 1675-1682, 2015.

Shah V.B., Orf G.S., Reisch S. et al.: Characterization and deposition of various light-harvesting antenna complexes by electrospray atomization. - Anal. Bioanal. Chem. 404: 23292338, 2012.

Shevela D., Björn L.O., Govindjee: Oxygenic Photosynthesis. In: Razeghifard R. (ed.): Natural and Artificial Photosynthesis: Solar Power as an Energy Source. Pp. 13-63. John Wiley \& Sons Inc., Hoboken 2013.

Sokol K.P., Mersch D., Hartmann V. et al.: Rational wiring of photosystem II to hierarchical indium tin oxide electrodes using redox polymers. - Energy Environ. Sci. 9: 3698-3709, 2016.

Spies J.A., Perets E.A., Fisher K.J. et al.: Collaboration between experiment and theory in solar fuels research. - Chem. Soc. Rev. 48: 1865-1873, 2019.

Stirbet A., Govindjee: On the relation between the Kautsky effect (chlorophyll $a$ fluorescence induction) and Photosystem II: Basics and applications of the OJIP fluorescence transient. J. Photoch. Photobio. B 104: 236-257, 2011.

Stirbet A., Lazár D., Kromdijk J., Govindjee: Chlorophyll a fluorescence induction: Can just a one-second measurement be used to quantify abiotic stress responses? - Photosynthetica 56: 86-104, 2018.

Szewczyk S., Białek R., Burdziński G., Gibasiewicz K.: Photovoltaic activity of electrodes based on intact photosystem I electrodeposited on bare conducting glass. - Photosynth. Res. 144: 1-12, 2020.

Terasaki N., Iwai M., Yamamoto N. et al.: Photocurrent generation properties of Histag-photosystem II immobilized on nanostructured gold electrode. - Thin Solid Films 516: 2553-2557, 2008.

Terasaki N., Yamamoto N., Hiraga T. et al:: Fabrication of novel photosystem I-gold nanoparticle hybrids and their photocurrent enhancement. - Thin Solid Films 499: 153-156, 2006.

Terasaki N., Yamamoto N., Hiraga T. et al.: Plugging a molecular wire into photosystem I: Reconstitution of the photoelectric conversion system on a gold electrode. - Angew. Chem. Int. Ed. 48: 1585-1587, 2009.

Tian W., Zhang H., Sibbons J. et al:: Photoelectrochemical water oxidation and longevous photoelectric conversion by a photosystem II electrode. - Adv. Energy Mater. 11: 2100911, 2021.

Tikhonov A.N.: pH-Dependent regulation of electron transport and ATP synthesis in chloroplasts. - Photosynth. Res. 116: 511-534, 2013.

Touloupakis E., Giannoudi L., Piletsky S.A. et al.: A multibiosensor based on immobilized Photosystem II on screenprinted electrodes for the detection of herbicides in river water. - Biosens. Bioelectron. 20: 1984-1992, 2005.

Trammell S.A., Spano A., Price R., Lebedev N.: Effect of protein orientation on electron transfer between photosynthetic reaction centers and carbon electrodes. - Biosens. Bioelectron. 21: 1023-1028, 2006.

Trammell S.A., Wang L., Zullo J.M. et al.: Orientated binding of photosynthetic reaction centers on gold using Ni-NTA selfassembled monolayers. - Biosens. Bioelectron. 19: 16491655,2004

Tucci M., Bombelli P., Howe C.J. et al.: A storable mediatorless electrochemical biosensor for herbicide detection. Microorganisms 7: 630, 2019.

Vittadello M., Gorbunov M.Y., Mastrogiovanni D.T. et al.: Photoelectron generation by photosystem II core complexes tethered to gold surfaces. - ChemSusChem 3: 471-475, 2010

Vogt L., Vinyard D.J., Khan S., Brudvig G.W.: Oxygen-evolving complex of Photosystem II: An analysis of second-shell residues and hydrogen-bonding networks. - Curr. Opin. Chem. Biol. 25: 152-158, 2015.

Voloshin R.A., Bedbenov V.S., Gabrielyan D.A. et al: Optimization and characterization of $\mathrm{TiO}_{2}$-based solar cell design using diverse plant pigments. - Int. J. Hydrogen Energ. 42: 8576-8585, 2017.

Voloshin R.A., Brady N.G., Zharmukhamedov S.K. et al.: Influence of osmolytes on the stability of thylakoid-based dye-sensitized solar cells. - Int. J. Energy Res. 43: 8878-8889, 2019.

Voloshin R.A., Kreslavski V.D., Zharmukhamedov S.K. et al.: Photoelectrochemical cells based on photosynthetic systems: a review. - Biofuel Res. J. 2: 227-235, 2015.

Voloshin R.A., Rodionova M.V., Zharmukhamedov S.K. et al.: Components of natural photosynthetic apparatus in solar cells. - In: Najafpour M.M. (ed.): Applied Photosynthesis New Progress. Pp. 161-188. InTech, Rijeka 2016.

Walker D.A.: Polarographic measurement of oxygen. - In: Hall D.O., Scurlock J.M.O., Bolhàr-Nordenkampf H.R. et al. (ed.): Photosynthesis and Production in a Changing Environment. 
Pp. 168-180. Springer, Dordrecht 1993.

Walker D.A., Sivak M.N., Prinsley R.T., Cheesbrough J.K.: Simultaneous measurement of oscillations in oxygen evolution and chlorophyll $a$ fluorescence in leaf pieces. Plant Physiol. 73: 542-549, 1983.

Walsh F.C., Arenas L.F., Ponce de León C. et al.: The continued development of reticulated vitreous carbon as a versatile electrode material: Structure, properties and applications. Electrochim. Acta 215: 566-591, 2016.

Wang P., Zhao F., Hartmann V. et al.: Reassessing the rationale behind herbicide biosensors: The case of a photosystem II/ redox polymer-based bioelectrodefs. - Bioelectrochemistry 136: 107597, 2020.

Wang W.-Q., Chapman D.J., Barber J.: Inhibition of water splitting increases the susceptibility of photosystem II to photoinhibition. - Plant Physiol. 99: 16-20, 1992.

Weijermars R., Taylor P., Bahn O. et al.: Review of models and actors in energy mix optimization - can leader visions and decisions align with optimum model strategies for our future energy systems? - Energy Strategy Rev. 1: 5-18, 2012.

Wey L.T., Bombelli P., Chen X. et al:: The development of biophotovoltaic systems for power generation and biological analysis. - ChemElectroChem 6: 5375-5386, 2019.

Wiederrecht G.P., Seibert M., Govindjee, Wasielewski M.R.: Femtosecond photodichroism studies of isolated photosystem II reaction centers. - P. Natl. Acad. Sci. USA 91: 8999-9003, 1994.
Xuan M., Li J.: Photosystem II-based biomimetic assembly for enhanced photosynthesis. - Natl. Sci. Rev. 8: nwab051, 2021.

Yehezkeli O., Bedford N.M., Park E. et al:: Semiconductorbased, solar-driven photochemical cells for fuel generation from carbon dioxide in aqueous solutions. - ChemSusChem 9: 3188-3195, 2016.

Yehezkeli O., Tel-Vered R., Michaeli D. et al.: Photosystem I (PSI)/Photosystem II (PSII)-based photo-bioelectrochemical cells revealing directional generation of photocurrents. Small 9: 2970-2978, 2013.

Yehezkeli O., Tel-Vered R., Michaeli D. et al.: Photosynthetic reaction center-functionalized electrodes for photo-bioelectrochemical cells. - Photosynth. Res. 120: 71-85, 2014.

Yu D., Wang M., Zhu G. et al.: Enhanced photocurrent production by bio-dyes of photosynthetic macromolecules on designed TiO film. - Sci. Rep.-UK 5: 9375, 2015.

Zaspa A.A., Vitukhnovskaya L.A., Mamedova A.M. et al.: Photovoltage generation by photosystem II core complexes immobilized onto a Millipore filter on an indium tin oxide electrode. - J. Bioenerg. Biomembr. 52: 495-504, 2020.

Zhang J.Z., Reisner E.: Advancing photosystem II photoelectrochemistry for semi-artificial photosynthesis. - Nat. Rev. Chem. 4: 6-21, 2020.

Zhang J.Z., Sokol K.P., Paul N. et al.: Competing charge transfer pathways at the photosystem II-electrode interface. - Nat. Chem. Biol. 12: 1046-1052, 2016.

(C) The authors. This is an open access article distributed under the terms of the Creative Commons BY-NC-ND Licence. 